\title{
Knockdown of flotillin-2 impairs the proliferation of breast cancer cells through modulation of Akt/FOXO signaling
}

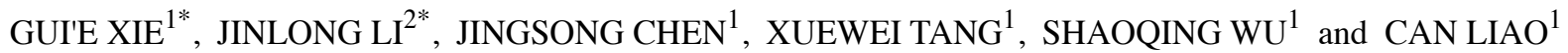 \\ ${ }^{1}$ Guangzhou Women and Children's Medical Center, Guangzhou Medical University, Guangzhou, Guangdong 510623; \\ ${ }^{2}$ School of Biotechnology, Southern Medical University, Guangzhou, Guangdong 510515, P.R. China
}

Received December 15, 2014; Accepted February 13, 2015

DOI: $10.3892 /$ or.2015.3826

\begin{abstract}
Lipid rafts, specialized domains in cell membranes, function as physical platforms for various molecules to coordinate a variety of signal transduction processes. Flotillin-2 (FLOT2), a marker of lipid rafts, is involved in the progression of cancer, yet the precise mechanism remains unclear. In the present study, we examined the effect of FLOT 2 on cell proliferation and found that silencing endogenous FLOT2 with shRNAs inhibited proliferation of breast cancer cells. Furthermore, the antiproliferative effect of silencing FLOT2 on breast cancer cells was associated with upregulation of cyclin-dependent kinase $(\mathrm{CDK})$ inhibitors $\mathrm{p} 21^{\mathrm{Cip} 1}$ and $\mathrm{p} 27^{\mathrm{Kip} 1}$. Moreover, we further demonstrated that the silencing of FLOT2 enhanced the transcriptional activity of FOXO factors by decreasing its phosphorylation through inhibiting the PI3K/Akt signaling pathway. Taken together, our results provide the first demonstration of a novel mechanism by which FLOT2 induces proliferation of breast cancer cells, and our findings suggest that FLOT2 plays an important role in oncogenesis of breast cancer and thereby may be a potential target for human breast cancer treatment.
\end{abstract}

\section{Introduction}

Breast cancer is the most common malignancy in females worldwide $(1,2)$. Despite great advances in diagnosis and appropriate systemic therapy, the mortality of breast cancer remains high, accounting for $14 \%$ of the total cancer-related deaths (3). Identifying key molecules contributing to the malignant properties of breast cancer cells is essential for future development of new and effective anti-breast cancer approaches.

Correspondence to: Dr Can Liao or Dr Shaoqing Wu, Guangzhou Women and Children's Medical Center, Guangzhou Medical University, Guangzhou, Guangdong 501623, P.R. China

E-mail: liaocan2014@126.com

E-mail: wushaoqing2014@126.com

${ }^{*}$ Contributed equally

Key words: flotillin-2, breast cancer, proliferation, Akt, FOXO
Flotillins, also known as reggie proteins, are markers of lipid rafts that contain two ubiquitously expressed and highly conserved homologous isoforms, i.e., flotillin-1 (FLOT1) and FLOT2 $(4,5)$. Flotillin proteins play important roles in various cellular processes, such as adhesion, actin cytoskeletal reorganization, endocytosis, phagocytosis and transduction of cellular signals $(6,7)$. Apart from the functions of flotillins in the cellular and organelle membranes, FLOT2 has been reported to be involved in oncogenesis. Hazarika et al showed that overexpression of FLOT2 was associated with human melanoma progression and lymph node metastasis (8). In gastric cancer, FLOT2 was reported as an independent prognostic factor (9), whereas in head and neck cancer FLOT2 overexpression was reported to show a strong predictive value for the development of metastases (10). Yan et al showed that upregulation of FLOT2 was associated with renal cell carcinoma progression (11). In nasopharyngeal carcinoma, the expression of FLOT2 was confirmed to be an independent predicted factor for lymph node metastasis (12). Recently, in breast cancer, it was reported that FLOT2 was associated with cancer progression and poor survival outcomes (13), yet the precise mechanism of its oncogenic function remains unclear.

In the present study, we found that knockdown of FLOT2 inhibited proliferation of breast cancer cells. Mechanistic basis for such an antiproliferative effect of FLOT2 depletion may be linked to suppression of Akt phosphorylation and subsequent activation of FOXOs, which consequently promote upregulation of CDK inhibitors $\mathrm{p} 21^{\mathrm{Cip} 1}$ and $\mathrm{p} 27^{\mathrm{Kip} 1}$. Our findings suggest that FLOT2 plays a role in the proliferation of human breast cancer, indicating that FLOT2 may be a potential target for human breast cancer treatment.

\section{Materials and methods}

Cell lines. Breast cancer MCF-7 and MDA-MB-231 cell lines were grown in Dulbecco's modified Eagle's medium (DMEM) (Invitrogen, Carlsbad, CA, USA) supplemented with $10 \%$ fetal bovine serum (HyClone, Logan, UT, USA).

Vectors and gene transduction. Expression of FLOT2 was stably knocked down in MCF-7 and MDA-MB-231 cells using the pSUPER-retroviral vector and the oligonucleotides for FLOT2 as previously described for HeLa cells (14). Recombinant retroviral vectors were produced by transient 
cotransfection as previously described (15). Viral infection was performed serially, and stable cell lines expressing FLOT2-RNAis were selected with $0.5 \mu \mathrm{g} / \mathrm{ml}$ puromycin $48 \mathrm{~h}$ after infection. After a 10-day selection, whole cell lysates were fractionated on sodium dodecyl sulfate polyacrylamide gel electrophoresis (SDS-PAGE) to examine the level of FLOT2 protein.

Western blot analysis. Western blotting was performed according to standard methods as previously described (16), using anti-p-Akt (ser473), anti-Akt, anti-p-Rb (ser608), anti-Rb, anti-p-FOXO1 (ser256), anti-FOXO1, anti-p-FOXO3a (ser253), anti-FOXO3a, anti-p-FOXO4 (Ser193), anti-FOXO4, anti-cyclin A, anti-CDK4, anti-CDK6, anti-p21 ${ }^{\text {Cip1 }}$ and anti-p27 $7^{\text {Kipl }}$ (Cell Signaling Technology, Danvers, MA, USA); and anti-FLOT2 and anti- $\alpha$-tubulin (Sigma-Aldrich, St. Louis, MO, USA).

Real-time PCR. Total RNA from cultured cells was extracted using the RNeasy kit (Qiagen, Crawley, UK). Each cDNA template was made from total RNA with a reverse transcriptase kit according to the manufacturer's instructions (Invitrogen). Amplification reactions were performed using the SYBR Premix Ex Taq ${ }^{\mathrm{TM}}$ (Takara Shuzo, Kyoto, Japan) in a $25 \mu \mathrm{l}$ volume. The following cycling parameters were used: $30 \mathrm{sec}$ at $95^{\circ} \mathrm{C}$ for initial denaturing, $5 \mathrm{sec}$ at $95^{\circ} \mathrm{C}$ for denaturing and $30 \mathrm{sec}$ at $60^{\circ} \mathrm{C}$ for annealing and extension for a total of 40 cycles. The fold-change in mRNA was calculated by the $2^{-\Delta \Delta C t}$ method. All samples were normalized to GAPDH. The primer sequences used were: p21 cip1-up, 5'-CGATGC CAACCTCCTCAACGA-3' and p21 ${ }^{\text {Cip1 }}$-dn, 5'-TCGCAGACC

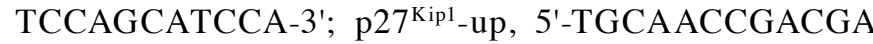
TTCTTCTACTCAA-3' and p27 $7^{\mathrm{Kip1}}$-dn, 5'-CAAGCAGTGATG TATCTGATAAACAAGGA-3'; GAPDH-up, 5'-ACCACAGTC CATGCCATCAC-3' and GAPDH-dn, 5'-TCCACCACC CTGTTGCTGTA-3'.

3-(4,5-Dimethyl-2-thiazolyl)-2,5-diphenyl-2H-tetrazolium bromide (MTT) assay. MTT assay was performed as previously described (17). Briefly, cells were seeded in 96-well flat-bottom plates at a density of $0.2 \times 10^{4}$ cells/well. At each time point, cells were stained with $100 \mu$ l sterile MTT dye $(0.5 \mathrm{mg} / \mathrm{ml})$ for $4 \mathrm{~h}$ at $37^{\circ} \mathrm{C}$, followed by removal of the culture medium and addition of $150 \mu \mathrm{l}$ of dimethyl sulfoxide (DMSO) (both from Sigma-Aldrich). The absorbance was measured at $570 \mathrm{~nm}$, with $630 \mathrm{~nm}$ as the reference wavelength. All experiments were performed in triplicates.

Colony formation assays. Cells were plated in 6-well plates $\left(3 \times 10^{2}\right.$ cells/well $)$ and cultured for 10 days. The colonies were stained with $1 \%$ crystal violet for $30 \mathrm{sec}$ after fixation with $10 \%$ formaldehyde for $5 \mathrm{~min}$.

Bromodeoxyuridine (BrdUrd) labeling and immunofluorescence. Cells were plated on coverslips (Fisher Scientific, Pittsburgh, PA, USA). After $24 \mathrm{~h}$, the cells were incubated with BrdUrd for $1 \mathrm{~h}$ and stained with the anti-BrdUrd antibody (Upstate, Temecula, CA, USA) according to the manufacturer's instructions. Gray level images were acquired under a laser scanning microscope (Zeiss Axiovert 100M; Carl Zeiss, Germany).

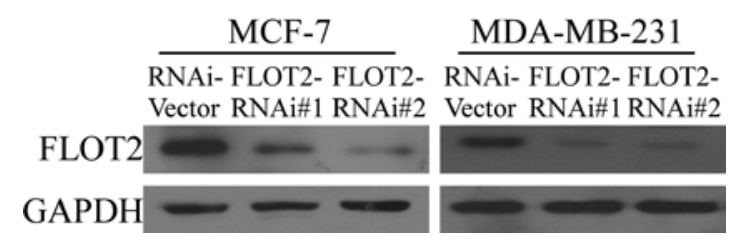

Figure 1. Knockdown of FLOT2 in two specific shRNA-transduced stable breast cancer cell lines. Expression of FLOT2 was examined in the indicated cells. GAPDH was used as a loading control. FLOT2, flotillin-2.

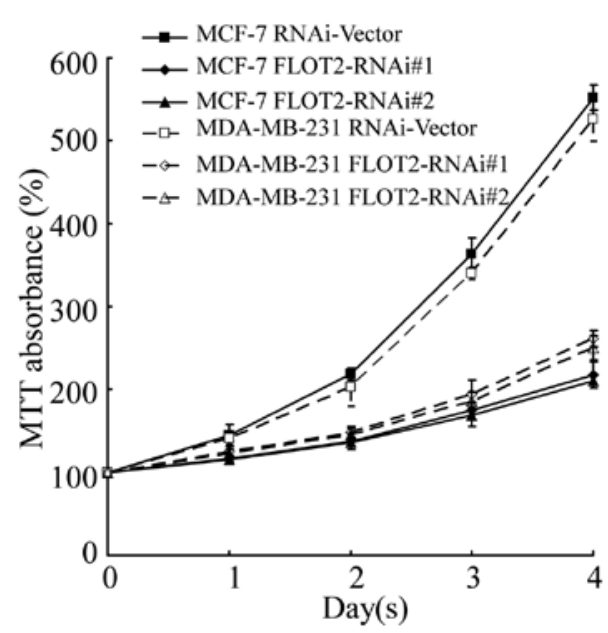

Figure 2. Knockdown of endogenous FLOT2 inhibits cell growth as determined by MTT assay. Cells were seeded in 96-well plates. At each time point, the cell viability was determined by MTT assay. Data points are presented as means \pm SD of triplicate experiments. FLOT2, flotillin-2.

Flow cytometry. Cells were harvested, washed with cold phosphate-buffered saline (PBS) and processed for cell cycle analysis using flow cytometry. Briefly, the cells were fixed in $75 \%$ ethanol and stored at $-20^{\circ} \mathrm{C}$ for later analysis. The fixed cells were centrifuged at $1,000 \mathrm{rpm}$ and washed with cold PBS twice. RNase A ( $20 \mu \mathrm{g} / \mathrm{ml}$ final concentration) and propidium iodide (PI) staining solution (50 $\mu \mathrm{g} / \mathrm{ml}$ final concentration) was added to the cells and incubated for $30 \mathrm{~min}$ at $37^{\circ} \mathrm{C}$ in the dark. Fifty thousand cells were analyzed using a FACSCalibur instrument (Becton-Dickinson, San Jose, CA, USA).

Statistical analysis. The data given in the text are expressed as means \pm standard deviations (SD). Comparisons between groups for statistical significance were carried out with a two-tailed Student's t-test. In all cases, $\mathrm{p}<0.05$ was considered to indicate a statistically significant result.

\section{Results}

Downregulation of FLOT2 inhibits the proliferation of breast cancer cells. To evaluate the biological function of FLOT2 in breast cancer, we constructed FLOT2-knockdown cell models using two FLOT2-specific shRNAs. As shown in Fig. 1, both shRNAs effectively knocked down the expression of endogenous FLOT2 protein in both the MCF-7 and MDA-MB-231 cells. An MTT assay showed that depletion of FLOT2 expression caused a significant reduction in viability of both MCF-7 and MDA-MB-231 breast cancer cell lines (Fig. 2), and 
A

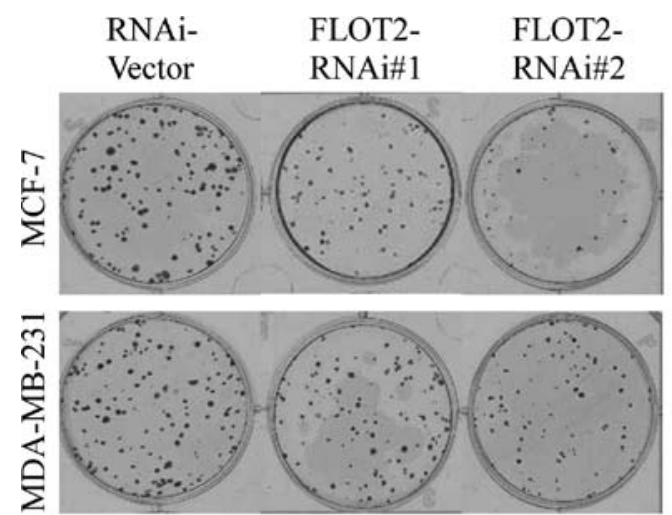

B

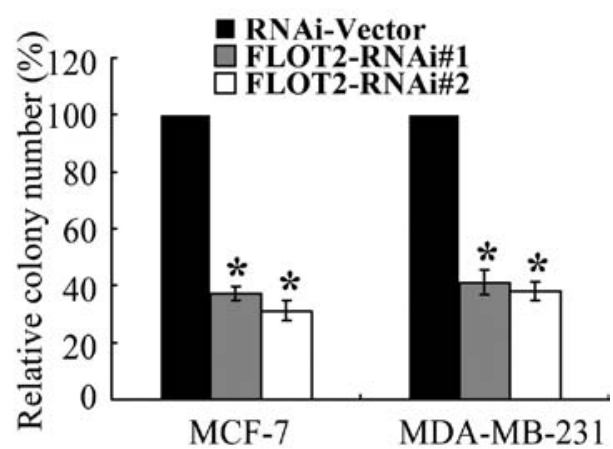

Figure 3. Silencing of endogenous FLOT2 inhibits cell growth as determined by colony formation assay. (A) Representative images of the crystal violet-stained cells. (B) Quantification of crystal violet-stained cells. Error bars represent SD calculated from three independent experiments. "p $<0.05$; significant differences compared with the control. FLOT2, flotillin-2.

A

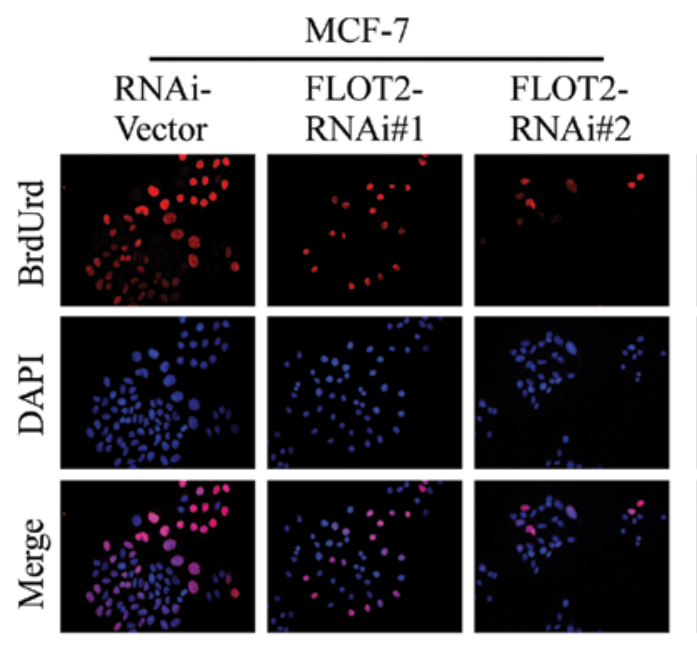

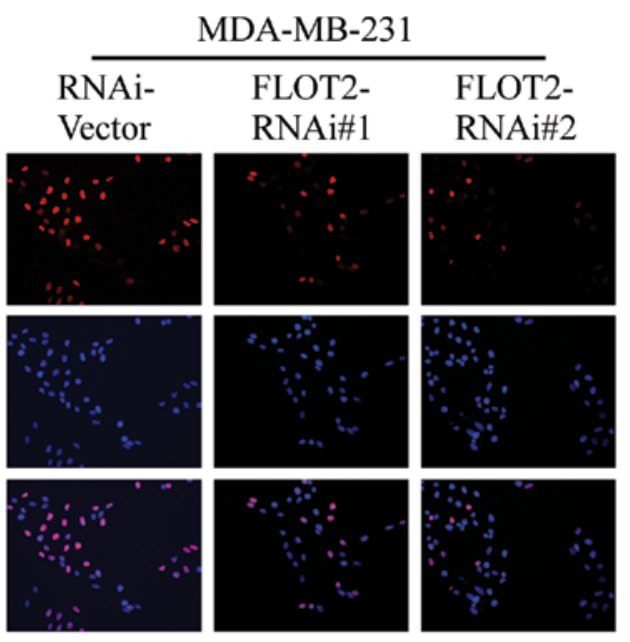

B

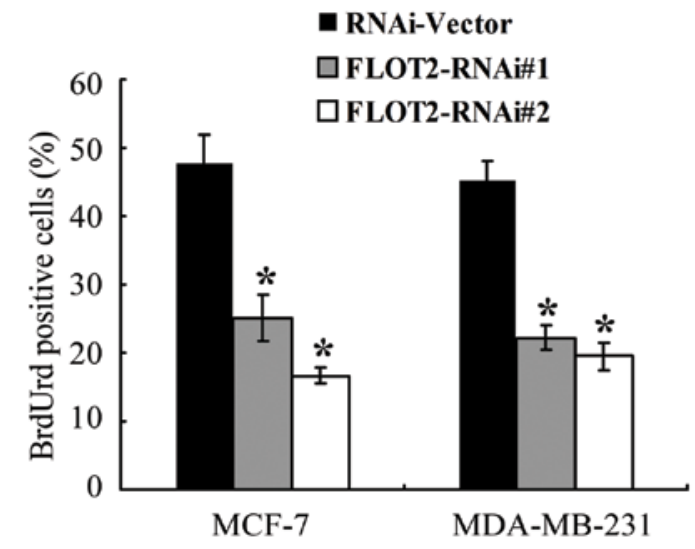

Figure 4. BrdUrd labelling assay of FLOT2-knockdown breast cancer cells. (A) Representative images of BrdUrd-incorporating cells in vector-infected cells and two FLOT2 shRNA-infected cell lines. (B) Quantification of BrdUrd-incorporating cells in indicated cells. * $\mathrm{p}<0.05$; significant differences compared with the control. FLOT2, flotillin-2.

these results were further confirmed by a colony formation assay (Fig. 3). These data suggest that FLOT2 may be involved in promoting the proliferation of breast cancer cells.

Silencing of FLOT2 results in the G1-S phase cell cycle arrest of breast cancer cells. To investigate the mechanism that mediates the proliferation-promoting function of FLOT2, a BrdUrd incorporation assay was performed. As shown in Fig. 4, the silencing of FLOT2 in the MCF-7 and MDA-MB231 cells markedly decreased the percentages of cells with incorporated BrdUrd. Flow cytometric analysis showed that downregulation of FLOT2 significantly increased the percentage of cells in the G0/G1 peak but decreased the percentage of cells in the S peak (Fig. 5). These results suggest 

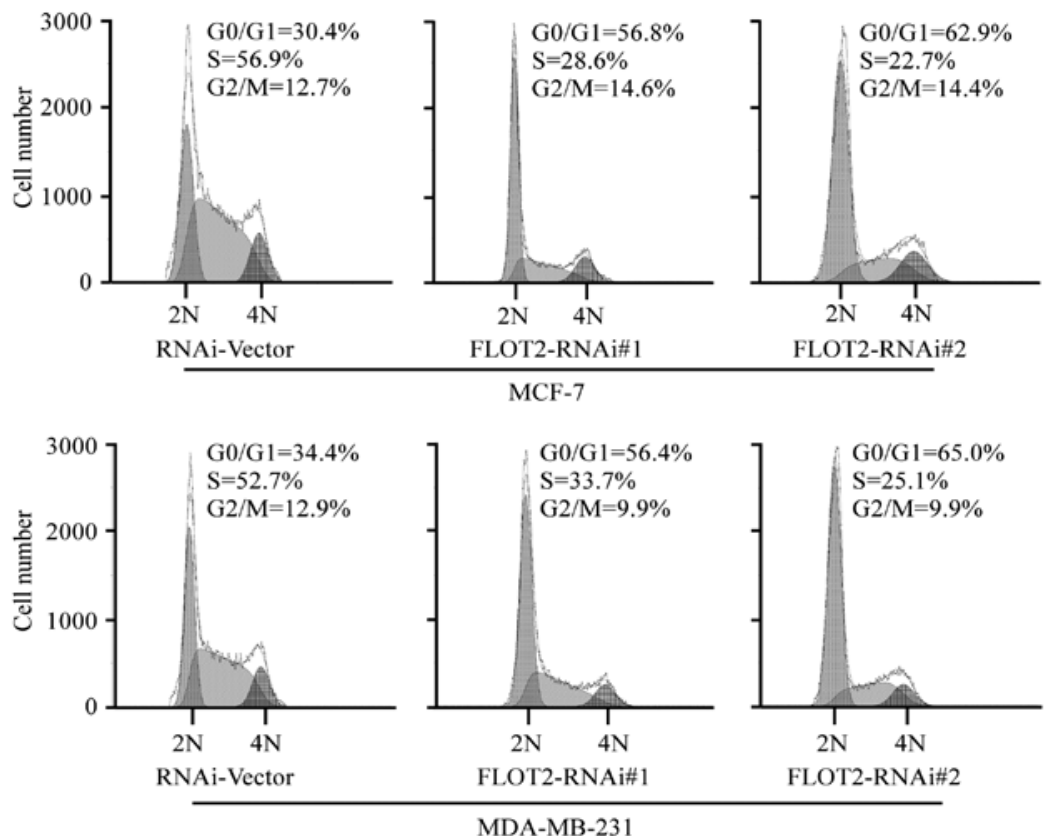

Figure 5. Depletion of FLOT2 induces G1-S phase arrest of breast cancer cells. Flow cytometric analysis of the indicated breast cancer cells infected with scramble vector or FLOT2 shRNAs. FLOT2, flotillin-2.

A

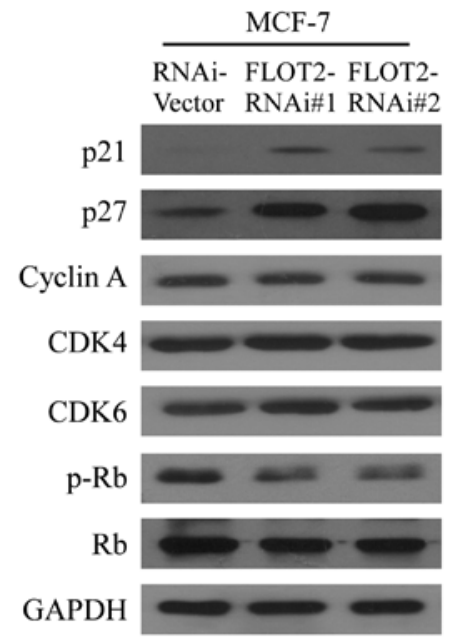

B

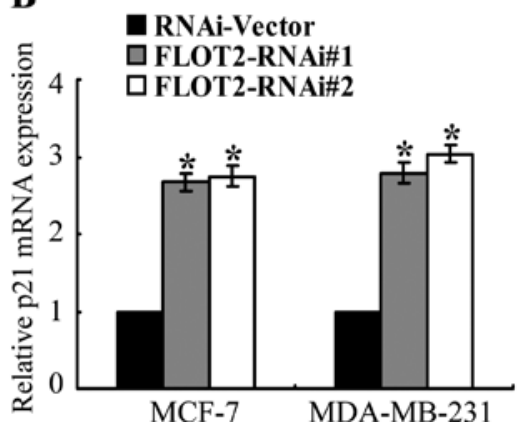

\section{MDA-MB-231}

RNAi- FLOT2- FLOT2-

Vector RNAi\#1 RNAi\#2
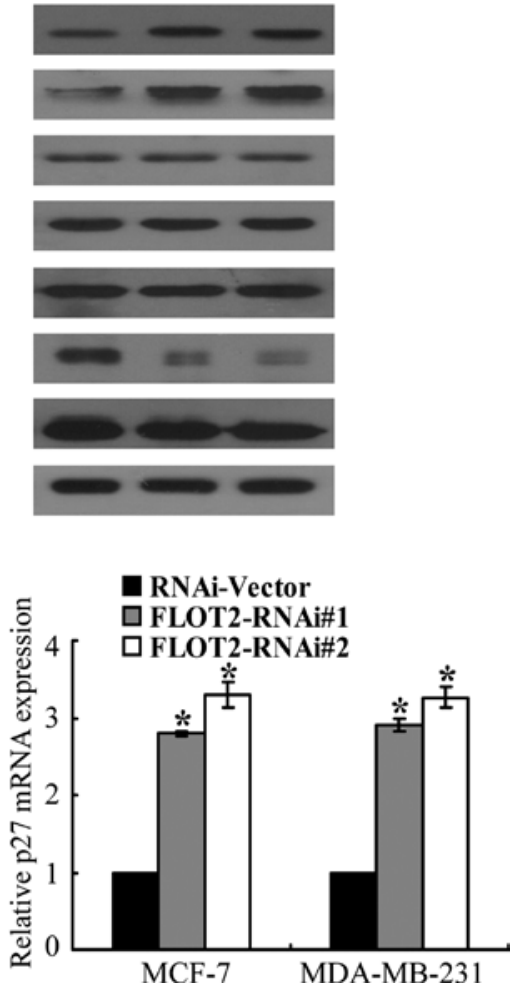

Figure 6. FLOT2 regulates cell cycle inhibitors $\mathrm{p} 21^{\mathrm{Cip1}}$ and $\mathrm{p} 27^{\mathrm{Kip} 1}$ in breast cancer cells. (A) Western blot analysis of p21 ${ }^{\mathrm{Cip} 1}$, p2 $7^{\mathrm{Kip} 1}$, cyclin A, CDK4, CDK6, $\mathrm{p}-\mathrm{Rb}$ and total $\mathrm{Rb}$ proteins in the indicated breast cancer cell lines. (B) Relative mRNA expression of p21 ${ }^{\text {Cipl }}$ (left panel) and p27 $7^{\text {Kipl }}$ (right panel) in the indicated breast cancer cell lines was determined by real-time PCR. Expression levels were normalized to GAPDH. Error bars represent SD calculated from three independent experiments. " $\mathrm{p}<0.05$; significant difference compared with the control. FLOT2, flotillin-2.

that the silencing of FLOT2 induces G1-S phase arrest of breast cancer cells.
Silencing of FLOT2 upregulates cell cycle inhibitors $p 21^{\text {Cipl }}$ and $p 27^{\text {Kipl }}$ in breast cancer cells. The observed correlation of 


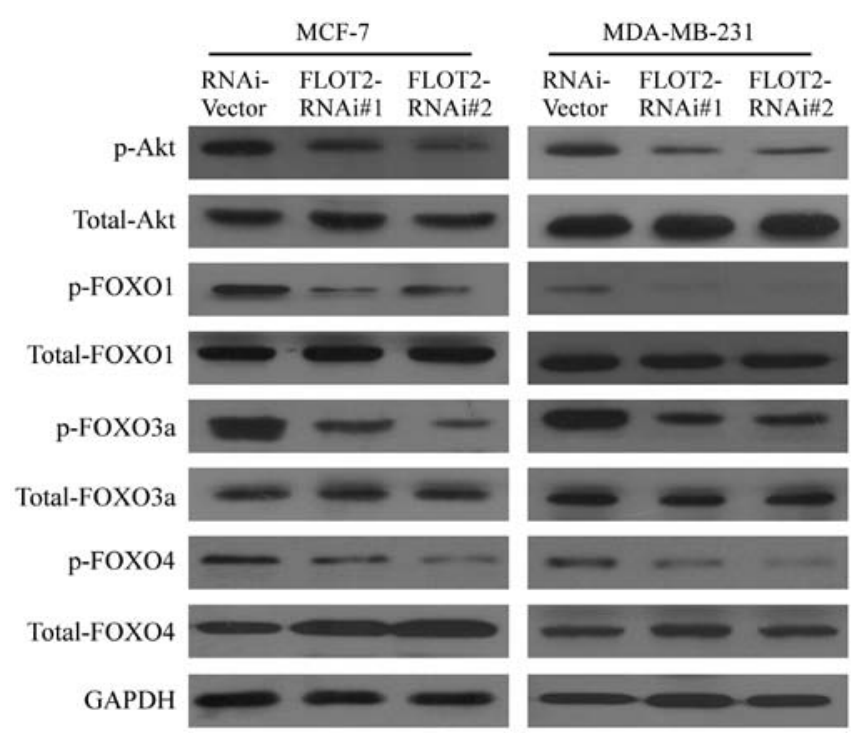

Figure 7. Effect of the silencing of FLOT2 on the Akt/FOXO signaling pathway in breast cancer cells. Western blot analysis of p-Akt, total Akt, p-FOXO1, total FOXO1, p-FOXO3a, total FOXO3a, p-FOXO4 and total FOXO4 protein in the indicated breast cancer cell lines. GAPDH was used as a loading control. FLOT2, flotillin-2.

deregulated FLOT2 expression with the proliferation of breast cancer cells prompted us to further investigate the possibility that cell cycle regulators may mediate the modulation by FLOT2. As shown in Fig. 6A, western blot analysis revealed that the silencing of FLOT2 had no effect on the expression of cyclin A, CDK4 and CDK6, all of which are cell cycle promoters. Instead, the expression levels of two CDK inhibitors, $\mathrm{p} 21^{\mathrm{Cip} 1}$ and $\mathrm{p} 27^{\mathrm{Kip} 1}$, were markedly upregulated in the FLOT2 shRNA-transduced cells at both the protein (Fig. 6A) and the mRNA level (Fig. 6B). As expected, the phosphorylation level of $\mathrm{Rb}$, the downstream target protein of $\mathrm{CDK}$, was shown to be suppressed in the FLOT2-silenced cells (Fig. 6A), further supporting the notion that FLOT2 is involved in the regulation of proliferation of breast cancer cells.

Silencing of FLOT2 enhances the transcriptional activity of FOXO factors via inhibiting Akt activation. The previous finding that the expression of $\mathrm{p} 21^{\mathrm{Cip} 1}$ and $\mathrm{p} 27^{\mathrm{Kip} 1}$ could be transcriptionally regulated by FOXO family transcriptional factors $(18,19)$ prompted us to test whether FLOT2 modulates the activity of FOXO factors. As shown in Fig. 7, western blot analysis revealed that the phosphorylation levels of FOXO1, FOXO3a and FOXO4 were decreased in FLOT2 shRNAinfected cells, compared with those in the vector-control cells. It is known that phosphorylation of FOXOs is mediated through activation of PI3K/Akt signaling (20-22). Thus, we further examined whether FLOT2 activated the PI3K/ Akt pathway. As shown in Fig. 7, downregulation of FLOT2 decreased the phosphorylation of Akt in both the MCF-7 and MDA-MB-231 cells as compared with the transduction control cells. Taken together, these data revealed that the observed upregulation of cell cycle inhibitors p21 $1^{\mathrm{Cip} 1}$ and $\mathrm{p} 27^{\mathrm{Kip} 1}$ caused by the silencing of FLOT2 was associated with inhibition of Akt kinase activity and subsequently enhanced transcriptional activity of FOXO factors.

\section{Discussion}

This study demonstrated that knockdown of endogenous FLOT2, a lipid raft specific protein, inhibited the proliferation of breast cancer cells. We showed that silencing of FLOT2 using RNAi resulted in suppression of Akt phosphorylation and subsequent activation of FOXOs, which led to the upregulation of $\mathrm{CDK}$ inhibitors $\mathrm{p} 21^{\mathrm{Cip} 1}$ and $\mathrm{p} 27^{\mathrm{Kip} 1}$. These findings provide new insights into the potential role of the upregulation of FLOT2 in promoting oncogenesis and progression of breast cancer.

Oncogenesis is a complex multi-step process, characterized by uncontrolled cell growth and tumor formation. During oncogenesis cells proliferate in a progressive, deregulated manner. Uncontrolled cell growth is associated with various alterations in genes or proteins related to regulation of proliferation, cell death and genetic stability, such as tumorsuppressor genes, oncogenes, growth factors and cell adhesion molecules (23). Thus, identification of genes and their products involved in the molecular events leading to oncogenesis is the key to the development of effective therapeutic strategies.

A correlation of FLOT2 with cancer development and progression has recently been demonstrated by studies from several groups, in which FLOT2 was found to be expressed at high levels in various types of human cancers, including head and neck cancer, melanoma, gastric cancer, nasopharyngeal carcinoma and breast cancer (8-13). Consistent with these clinical findings, at the cellular level we found that depletion of FLOT2 suppressed the proliferation of breast cancer cells, a key biological event essential for cancer development and progression. The experiments on the effects of FLOT2 depletion on cell viability, colony-formation ability and BrdUrd incorporation confirmed that FLOT2 is a proliferation promotor. Further experiments showed that silencing of FLOT2 in breast cancer cells enhanced G1-S phase arrest. Such a connection between FLOT2 and G1/S phase transition was shown to be mechanistically mediated by the cell cycle inhibitors $\mathrm{p} 21^{\mathrm{Cip} 1}$ and $\mathrm{p} 27^{\mathrm{Kip} 1}$, which the present study demonstrated to be upregulated by knocking down FLOT2 in the breast cancer cells.

FOXO proteins are a family of transcription factors that play important roles in regulating the expression of genes involved in a variety of biological processes, such as proliferation, differentiation, stress response and cellular apoptosis $(24,25)$. It has been demonstrated that FOXO proteins act as tumor suppressors as evidenced by its transcriptional induction of CDK inhibitors, including $\mathrm{p} 21^{\mathrm{Cip} 1}, \mathrm{p} 27^{\mathrm{Kip} 1}$ and $\mathrm{p} 57^{\mathrm{kip} 2}$. It has been demonstrated that phosphorylation of FOXOs by Akt leads to FOXO nuclear/cytoplasmic translocation and subsequent degradation via the ubiquitin-proteasome system $(26,27)$. In the present study, decreased phosphorylation, and subsequent increased transcriptional activity, of FOXO factors (FOXO1, FOXO3a and FOXO4), which are known activators for $\mathrm{p} 21^{\text {Cip1 }}$ and $\mathrm{p} 27^{\mathrm{Kip} 1}$ transcription, was found when FLOT2 expression was depleted and such an effect was likely to be mediated by suppression of Akt phosphorylation.

In summary, our finding that knockdown of FLOT2, a marker of lipid rafts, inhibited the proliferation of breast cancer cells through modulation of the Akt/FOXO/p21/p27 pathway illustrates a new mode of action in the molecular mechanism 
underlying the oncogenesis of breast cancer. Understanding the precise role played by FLOT2 in breast cancer progression will not only increase our knowledge of the biology of breast cancer but may also enable development of a novel therapeutic strategy via suppression of FLOT2.

\section{Acknowledgements}

The present study was supported by a grant from the National Natural Science Foundation of China (no. 81101682), a Science and Technology Planning Project of Guangzhou Municipal Health Bureau (no. 201102A213045), and a Ph.D. Start-up Fund of Guangzhou Women and Children's Medical Center (no. 201012).

\section{References}

1. Friedenreich CM: Physical activity and breast cancer: Review of the epidemiologic evidence and biologic mechanisms. Recent Results Cancer Res 188: 125-139, 2011.

2. Zheng L, Zhou B, Meng X, Zhu W, Zuo A, Wang X, Jiang R and Yu S: A model of spontaneous mouse mammary tumor for human estrogen receptor- and progesterone receptor-negative breast cancer. Int J Oncol 45: 2241-2249, 2014.

3. Jemal A, Bray F, Center MM, Ferlay J, Ward E and Forman D: Global cancer statistics. CA Cancer J Clin 61: 69-90, 2011.

4. Guan Y, Song H, Zhang G and Ai X: Overexpression of flotillin-1 is involved in proliferation and recurrence of bladder transitional cell carcinoma. Oncol Rep 32: 748-754, 2014.

5. Babuke T and Tikkanen R: Dissecting the molecular function of reggie/flotillin proteins. Eur J Cell Biol 86: 525-532, 2007.

6. Lin C, Wu Z, Lin X, Yu C, Shi T, Zeng Y, Wang X, Li J and Song L: Knockdown of FLOT1 impairs cell proliferation and tumorigenicity in breast cancer through upregulation of FOXO3a. Clin Cancer Res 17: 3089-3099, 2011.

7. Langhorst MF, Reuter A and Stuermer CA: Scaffolding microdomains and beyond: The function of reggie/flotillin proteins. Cell Mol Life Sci 62: 2228-2240, 2005.

8. Hazarika P, McCarty MF, Prieto VG, George S, Babu D, Koul D, Bar-Eli M and Duvic M: Up-regulation of Flotillin-2 is associated with melanoma progression and modulates expression of the thrombin receptor protease activated receptor 1 . Cancer Res 64: 7361-7369, 2004

9. Zhu Z, Wang J, Sun Z, Sun X, Wang Z and Xu H: Flotillin2 expression correlates with HER2 levels and poor prognosis in gastric cancer. PLoS One 8: e62365, 2013.

10. Rickman DS, Millon R, De Reynies A, Thomas E, Wasylyk C, Muller D, Abecassis J and Wasylyk B: Prediction of future metastasis and molecular characterization of head and neck squamous-cell carcinoma based on transcriptome and genome analysis by microarrays. Oncogene 27: 6607-6622, 2008.

11. Yan Y, Yang FQ, Zhang HM, Che J and Zheng JH: Up-regulation of flotillin-2 is associated with renal cell carcinoma progression. Tumour Biol 35: 10479-10486, 2014.
12. Wen Q, Li J, Wang W, et al: Increased expression of flotillin-2 protein as a novel biomarker for lymph node metastasis in nasopharyngeal carcinoma. PLoS One 9: e101676, 2014.

13. Wang X, Yang Q, Guo L, Li XH, Zhao XH, Song LB and Lin HX: Flotillin-2 is associated with breast cancer progression and poor survival outcomes. J Transl Med 11: 190, 2013.

14. Pust S, Dyve AB, Torgersen ML, van Deurs B and Sandvig K: Interplay between toxin transport and flotillin localization. PLoS One 5: e8844, 2010.

15. Hahn WC, Dessain SK, Brooks MW, King JE, Elenbaas B, Sabatini DM, DeCaprio JA and Weinberg RA: Enumeration of the simian virus 40 early region elements necessary for human cell transformation. Mol Cell Biol 22: 2111-2123, 2002.

16. Xie G, Tang H, Wu S, Chen J, Liu J and Liao C: The cyclin-dependent kinase inhibitor SNS-032 induces apoptosis in breast cancer cells via depletion of Mcl-1 and X-linked inhibitor of apoptosis protein and displays antitumor activity in vivo. Int J Oncol 45: 804-812, 2014

17. Xie G, Zhu X, Li Q, et al: SZ-685C, a marine anthraquinone, is a potent inducer of apoptosis with anticancer activity by suppression of the Akt/FOXO pathway. Br J Pharmacol 159: 689-697, 2010.

18. Nakamura N, Ramaswamy S, Vazquez F, Signoretti S, Loda M and Sellers WR: Forkhead transcription factors are critical effectors of cell death and cell cycle arrest downstream of PTEN. Mol Cell Biol 20: 8969-8982, 2000.

19. Cardozo $\mathrm{T}$ and Pagano M: The SCF ubiquitin ligase: Insights into a molecular machine. Nat Rev Mol Cell Biol 5: 739-751, 2004.

20. Brunet A, Bonni A, Zigmond MJ, Lin MZ, Juo P, Hu LS, Anderson MJ, Arden KC, Blenis J and Greenberg ME: Akt promotes cell survival by phosphorylating and inhibiting a Forkhead transcription factor. Cell 96: 857-868, 1999.

21. Burgering BM: A brief introduction to FOXOlogy. Oncogene 27: 2258-2262, 2008.

22. Yu W, Wang J, Ma L, Tang X, Qiao Y, Pan Q, Yu Y and Sun F: CD166 plays a pro-carcinogenic role in liver cancer cells via inhibition of FOXO proteins through AKT. Oncol Rep 32: 677-683, 2014.

23. Doerfler W, Hohlweg U, Müller K, Remus R, Heller H and Hertz J: Foreign DNA integration - perturbations of the genome - oncogenesis. Ann NY Acad Sci 945: 276-288, 2001.

24. Arden KC: FoxOs in tumor suppression and stem cell maintenance. Cell 128: 235-237, 2007.

25. Park SH, Lee JH, Berek JS and Hu MC: Auranofin displays anticancer activity against ovarian cancer cells through FOXO3 activation independent of p53. Int J Oncol 45: 1691-1698, 2014.

26. Huang H, Regan KM, Wang F, Wang D, Smith DI, van Deursen JM and Tindall DJ: Skp2 inhibits FOXO1 in tumor suppression through ubiquitin-mediated degradation. Proc Natl Acad Sci USA 102: 1649-1654, 2005.

27. Seoane J, Le HV, Shen L, Anderson SA and Massagué J: Integration of Smad and forkhead pathways in the control of neuroepithelial and glioblastoma cell proliferation. Cell 117: 211-223, 2004. 